Urban Design and Planning

Volume 166 Issue DP4

Evidence-based design: satellite positioning studies of city centre user groups

Van der Spek, Van Langelaar and Kickert

ice proceedings
Proceedings of the Institution of Civil Engineers

Urban Design and Planning 166 August 2013 Issue DP4

Pages 206-216 http://dx.doi.org/10.1680/udap.11.00028 Paper 1100028

Received 13/07/2011_Accepted 20/09/2012

Published online 28/01/2012

Keywords: building, structures \& design/research \&

development/town and city planning ice

Institution of Civil Engineers

\title{
Evidence-based design: satellite positioning studies of city centre user groups
}

1 Stefan Christiaan Van der Spek MSc, PhD Associate professor, Chair of Urban Design, Delft University of Technology, Faculty of Architecture, Department of Urbanism, Delft, the Netherlands

2 Christine Maria Van Langelaar MSC Technical assistant, Chair of Urban Design, Delft University of
Technology, Faculty of Architecture, Department of Urbanism, Delft the Netherlands

3 Conrad Christiaan Kickert MSC

PhD candidate, Taubman College of Architecture and Urban Planning, University of Michigan, Ann Arbor, USA
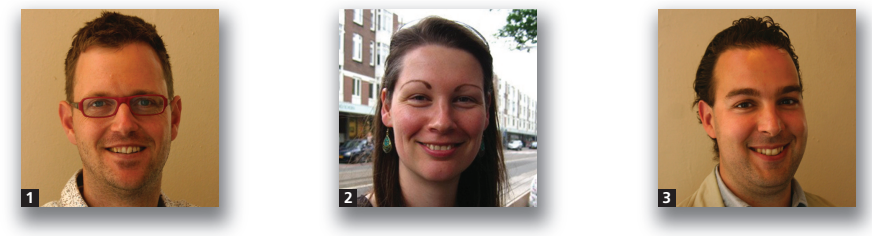

In an era of increasing competition between urban cores, positive pedestrian experiences become crucial in attracting visitors and retaining residents. The dichotomy between use and evaluation of public spaces enables the prioritisation of urban design and management interventions in an age of austerity. When spaces are highly used but evaluated as poor, they warrant improvements over other spaces. The results therefore substantiate evidence-based design that achieves significant yet cost-effective improvements of the city centre pedestrian experience. This paper presents an approach to understanding city centre pedestrian behaviour and experiences by deploying global positioning system tracking technology. This technology enables accurate measurement of routing and behaviour in public space. Differences between the use of public spaces in the city centre of Delft by visitors and residents are measured by tracking the behaviour of three user groups. This measured behaviour is supplemented by questionnaire results to understand the evaluation of public spaces in central Delft.

\section{Introduction}

\subsection{Vital cities}

For centuries town and city centres have claimed a central role in serving local residents and attracting visitors with shopping, cultural, leisure and civic facilities. The significance of urban cores has come under pressure in western society as they face increasing economic and social competition from decentralised urban development. Challenges range from problematic car accessibility and parking to the perceived inability to house space-intensive functions, such as larger retail and office units, efficiently and affordably (Jakle and Sculle, 2004; Taubman, 2007). As the urban core will inherently never be as easily accessible by car as suburbia, a major competitive edge over decentralised commercial and civic facilities has to come from a superior 'quality of experience'. In order to improve this intuitive perception of a positive inner city experience, it is necessary to recognise and measure the components of positive human-behaviour interaction, most notably from an evaluative standpoint (Carmona, 2010).

Beyond a reasoned and often proven need for diversity and activity (Jacobs, 1961), vitality and diversity of social life (Appleyard et al., 1981; Gehl et al., 2006a; Whyte, 1988) in order to increase the social, economic and environmental vitality and viability of town and city centres, this paper mainly focuses on the aspects of public space use patterns within urban cores. An attractive environment may correlate with an increased duration of public space use, which in turn may lead to an increase of street vitality (Jacobs, 1961; Gehl, 1971) with various potential benefits. Van der Hoeven et al. (2008) present a strong correlation between duration of stay in a city and the money spent during this stay. This conclusion is affirmed by studies conducted by Transport for London (Plowden, 2010). Beyond economic concentrations, urban cores also function as social and cultural hotspots in metropolitan regions where 
Urban Design and Planning

Volume 166 Issue DP4
Evidence-based design: satellite

positioning studies of city

centre user groups

Van der Spek, Van Langelaar and

Kickert high-quality public space encourages encounters (Hajer and Reijndorp, 2001).

In the dense western 'Randstad' conurbation in the Netherlands - comprising an area spanning Amsterdam, Rotterdam, Utrecht and The Hague - these challenges are intensified by swift interconnectivity between cities. As the Randstad transport networks allow for fast and easy intercity travel, competition between urban cores to become commercial and leisure destinations is mounting. Contemporary consumers are increasingly critical and spoiled for choice (Coleman, 2006). Providing visitors and residents alike with a high-quality city centre experience is crucial in this battle, as similar retail amenities can be found throughout the Randstad (Platform Binnenstadsmanagement, 2010)

On the one hand, experiences can be influenced by amenities on offer in city centres. Local shops and cultural facilities add a 'couleur locale' that distinguishes an urban core. On the other hand, the physical environment and most notably the quality of public space add significantly to positive experiences. The experiences of visitors and residents can be collected and evaluated. How do people think and feel about the city? What would they like to change and why?

Combining these experiences with behaviour metrics allows for a prioritisation of city centre investment strategies. Increased use of a certain public space does not necessarily imply a positive evaluation by its users. In an age of austerity, investments aimed at improving public spaces can be prioritised if it is understood which spaces are intensely used and evaluated as poor and vice versa. As Danish architect Jan Gehl notes, these environments warrant public space improvements. If environments are sparsely used but highly valued, they need to become better connected to their surroundings (Gehl et al., 2006b). In other words, the present study substantiates evidence-based strategic interventions.

\subsection{Research aim and questions}

In order to improve town and city centre environments for all users, it is important to know how different user groups navigate and evaluate the public space. Improvement of urban cores is often aimed at accommodating an increase in visitor amenities for shopping, leisure or culture. Yet vital environments and their measurement should also include residential populations, a fact increasingly acknowledged by policymakers (Jacobs, 1961; Montgomery, 1998).

This study will focus on the city centre of Delft, a city of about 100000 inhabitants with a sizable historic core that serves as the retail, leisure and cultural heart of the city and the region. Three groups are studied: visitors, city centre inhabitants and residents of adjacent neighbourhoods. Do these disparate groups use the public spaces in the city centre of Delft differently? And do they evaluate these spaces differently? Furthermore, are there discrepancies between use and evaluation of public space? Can the correlations and disparities between public space evaluation and patterns of use be embedded in strategic spatial design interventions?

\subsection{Global positioning systems in action}

In order to study patterns of public space use, this research uses satellite global positioning system (GPS) technology to track movements of respondents. This technology allows for the measurement of direction, speed and duration of stay and therefore intensity of use of public space. City centre use and experience can be measured in time and space by using GPS tracking technologies. As with every method, the use of GPS devices for this purpose has both advantages and disadvantages (Van Schaick and Van der Spek, 2008).

Not every place is suitable for a GPS tracking research project as there are both temporal and spatial limitations. As devices need to be returned to their point of origin, it is difficult to define suitable source points. This process requires a distribution point that respondents will return to. Clearly, in a parking garage people will return in order to pick up their car. For respondents arriving by other modes of transport this might not be the case. People can arrive by train and return using another transportation mode or station. This can limit the study of city centres, because a significant portion of visitors may arrive by modes other than a car, a group that is thus far difficult to approach with GPS devices. GPS tracking is also relatively labour intensive. First, a willing and representative group of respondents needs to be identified. Second, the GPS devices must be distributed, with one researcher only likely to distribute a few devices per day. Third, the data from the returned GPS devices must be collected in a systematic manner. Even with the intensive work required, the number of collected tracks is relatively low compared to conventional pedestrian counting methods.

Despite the disadvantages, the advantages of using GPS tracking technology are significant. The resulting datasets are incredibly rich and highly representative. First, devices can be set to register the location of subjects every few seconds. GPS tracks contain a high level of detail, which can be compared to the experience of people. The exact travelled route is mapped; therefore statements can be made about the city's network. Second, destinations of people can be found in the data, which makes it possible to connect activities to the land use plan. Consequently, the entire or partial duration of the trip can be registered in order to find out how much time people spend in the city or at a destination. In comparison with mind mapping, GPS data are very reliable and highly detailed. People often forget exactly where they went during the day and are often not 
Urban Design and Planning

Volume 166 Issue DP4
Evidence-based design: satellite

positioning studies of city

centre user groups

Van der Spek, Van Langelaar and

Kickert capable of drawing a trustworthy map by themselves (Janssens et al., 2008; Van Schaick and Van der Spek, 2007). Finally, conventional footfall counts cannot determine route choice or sojourning. Counts only reveal a certain amount of people on a limited amount of streets during a limited amount of time.

By adding a questionnaire with socio-demographic background information to the study, selections in the tracking data can be made. Do all male participants work outside the city of Delft? What kind of people visit the street markets? Do most people go to Amsterdam on a national holiday? A variety of questions can be asked and selections in the data can reveal interesting facts. Again, conventional footfall counts cannot determine the background of subjects, as they are not usually approached by researchers. Questionnaires can be focused on studying the evaluation of the city. Indeed, the more time people spend on the streets, the more street life will flourish. In addition, the questionnaire reveals how the participants experience the city centre. What are the good elements? What can be improved? The trips of one person provide individual behaviour. However, the combined data of all participants shows an intensity that represents a collective. Consequently, if you measure people's behaviour by tracking them and you ask them for an evaluation of the city, you can develop evidencebased design.

A third quality is that participants do not need to understand the technology. The GPS device is a simple black box with a button to turn it on and off, and most participants do not need to operate the device at all. Interest in smart phone Bluetooth and GPS tracking technology has increased owing to the much larger potential pool of subjects. However, the sample would then be biased toward (smart) phone owners, most likely a younger and more 'tech-savvy' demographic. With GPS tracking, participants can be selected randomly. The researcher can approach a large and demographically representative target group. However, owing to the large amount of highquality data, which contain great diversity, statistically there is a limit on the number of participants that a researcher can work with.

\subsection{Methodology}

Whereas previous GPS research (Shoval and Isaacson, 2010; Van der Spek, 2008) discusses results of one target group using a certain space, the present research aims to enhance these results by measuring the spatial behaviour and evaluation of three different groups.

In November 2009 the spatial behaviour of city centre visitors such as tourists was measured, focusing on their journey on foot through the centre after they had parked their car in one of two parking garages directly adjacent to the urban core. Visitors were followed from 10 a.m. until 6 p.m. during 4 days with a total of 80 GPS devices. This study was then supplemented in April and May 2010 by a study into city centre use by inhabitants of the centre itself and adjacent neighbourhoods within Delft. Eighty inhabitants were followed around the clock for a week.

Spatial-geographical results of both studies have been imported and mapped in ArcGIS. This research mainly focuses on the analysis and understanding of group behaviour. Widely divergent individual movements have been filtered out. Instead, track density has been mapped, enabling the recognition of overlapping routes that participants have taken. Furthermore, the locations of sojourning and destination spots have been distilled from the collected GPS data by measuring the duration of stay of a participant at a certain location.

Upon the return of the devices, participants completed a short questionnaire focused on their evaluation of public space and socio-demographic background. The resulting socio-demographic statistical inferences were produced in Excel (Van der Spek et al., 2009). The questionnaire measured participants' spatial evaluation by means of marking most and least liked locations on a printed map. These results have been compiled into synthesis maps with graphics software.

The behaviour of the three different pedestrian groups was compared, leading to conclusions about inter-group correlations or disparities. This behaviour pattern was correlated with the evaluation of public spaces. Participant questionnaires focused on experiences and evaluations of public space by asking for a substantiated evaluation of spaces in the city centre of Delft. These questionnaires have been augmented by desktop analysis of urban streetscapes in order to understand and explain pedestrian's behaviour and environmental evaluation. Combined, the behaviour and evaluation of public space enables conclusions about spatial design interventions backed by empirical evidence.

\section{Patterns of spatial behaviour among different user groups}

This section aims to define whether visitors and inhabitants of either the city centre itself or adjacent neighbourhoods show a different pattern of spatial behaviour in the city centre. The results per group are discussed in separate paragraphs, followed by a synthesis map correlating these results in a map and a set of conclusions.

\subsection{City centre visitors/tourists}

The first study aimed at tracking visitors. This group contained tourists from other countries and Dutch citizens who live far away from the Delft city centre, arriving in the city centre by car. A total of 325 respondents were handed a GPS device as they entered the centre of Delft on foot from two parking 
Urban Design and Planning

Volume 166 Issue DP4
Evidence-based design: satellite positioning studies of city

centre user groups

Van der Spek, Van Langelaar and Kickert garages to the south and west of the city centre. These garages are marked as ' $\mathrm{P}$ ' in Figure 1. This yielded 285 valid GPS tracks, 112 at the western Phoenix garage, 173 at the southern Zuidpoort garage. Interestingly only about $10 \%$ of participants from these garages were first-time visitors.

Concluding from this data, an analysis of highly used and nonused public spaces (indicated respectively by thick black and thin grey lines) is presented in Figure 2. This figure clearly illustrates that visitors use only a selective portion of the city centre, mainly to the southwest. This outcome correlates with previous GPS studies conducted in European cities such as Norwich and Koblenz (Van der Hoeven et al., 2008). A majority of respondents spend between 1 and $2 \mathrm{~h}$ in the city centre. Visitors in the Zuidpoort garage seem to visit the city centre for a somewhat shorter period than the Phoenix garage, perhaps owing to the closer proximity of retail shops to the former garage.

\subsection{City centre inhabitants}

The second research conducted in April and May 2010 focused on the use of the city centre by its inhabitants, not only as pedestrians but also using other modes of transport (such as bike, car, train and so on). A total of 18 respondents in ten households received a GPS device for tracking their behaviour for a week, registering a total of 72 pedestrian trips from 17 valid respondents, illustrated in Figure 3.

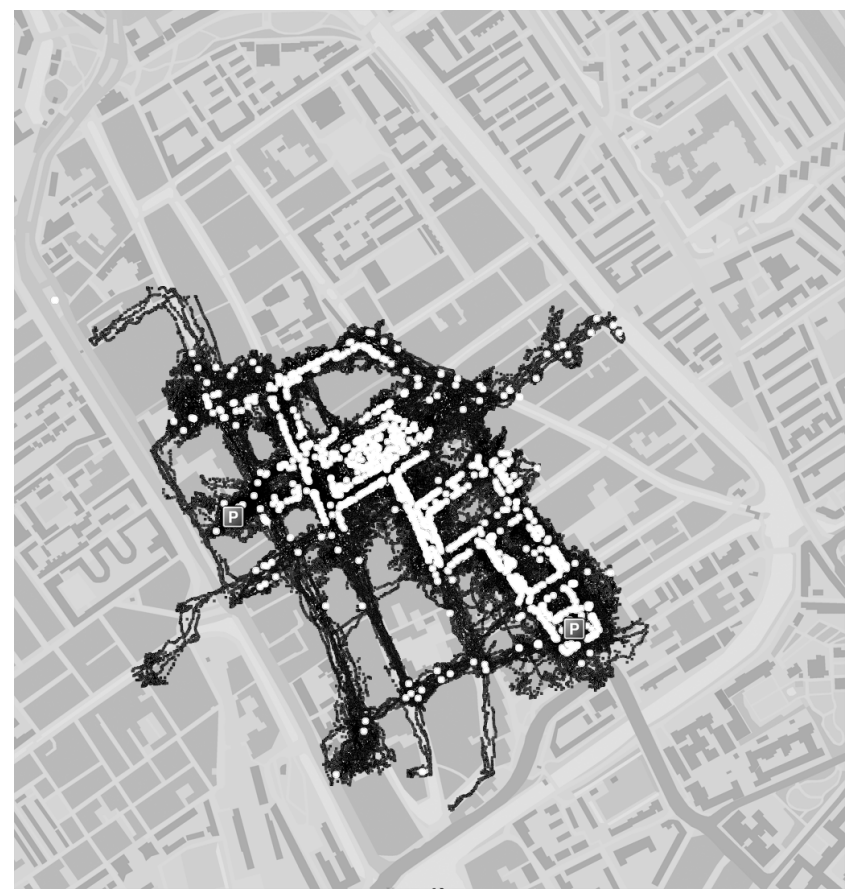

Figure 1. Pedestrian trips and destinations of visitors from both garages. Small black dots mark pedestrian routes whereas white dots mark visited destinations by pedestrians

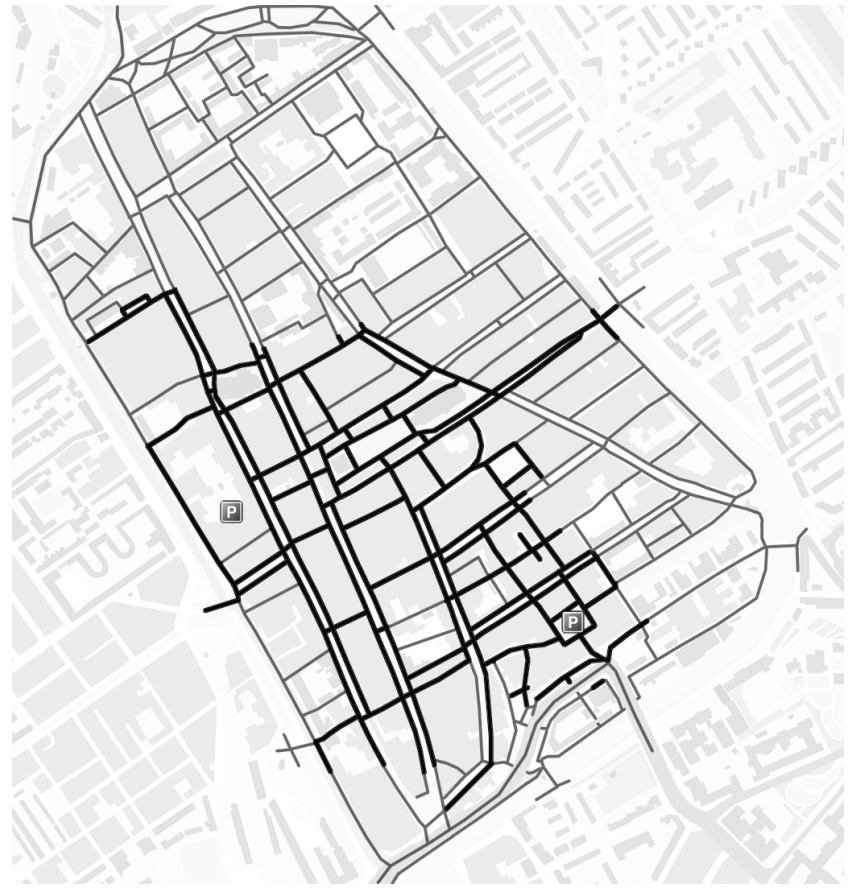

Figure 2. Streets highly used or unused by visitors. Highly used spaces are marked with thick black lines. Unused public spaces are marked in thin grey lines

As indicated in Figure 4, city centre inhabitants appear to use most of the same streets as visitors. On the other hand, city centre inhabitants do use certain streets that visitors forgo, such as local shopping streets on the north side of the city centre. Most city centre trips are undertaken for shopping, leisure and drinking and dining.

\subsection{Adjacent neighbourhood residents}

The 2010 study also focused on patterns of spatial behaviour by residents of neighbourhoods directly adjacent to the city centre of Delft. Tracks were separated by mode of transport, aiming to illustrate how nearby residents approached and used the city centre itself on foot. A total of 52 respondents in 29 households received a GPS device, with 33 devices from 19 households returning a total of 55 valid pedestrian tracks. These results are illustrated in Figure 5. The low number of pedestrian tracks per device can be ascribed to the fact that many journeys are undertaken by other modes of transport owing to the larger distance to the city centre. Only $30 \%$ of trips were made on foot, compared to $60 \%$ by bicycle.

Highly similar to city centre inhabitants, nearby residents use many of the same streets as visitors and tourists as indicated in Figure 6. They also use a range of other streets in the city centre, with a focus on the north and west of the city centre. 
Urban Design and Planning

Volume 166 Issue DP4
Evidence-based design: satellite positioning studies of city

centre user groups

Van der Spek, Van Langelaar and

Kickert

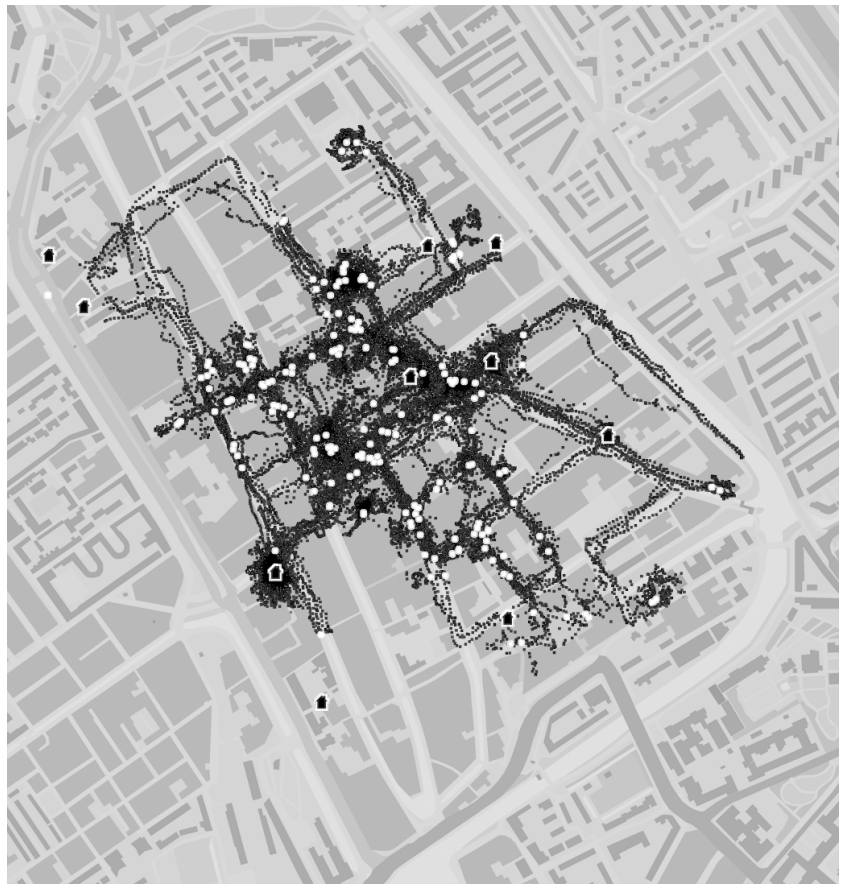

Figure 3. Trips and destinations of city centre inhabitants. Small black dots mark pedestrian routes whereas white dots mark visited destinations by pedestrians. Houses have black shapes with a white circumference

\subsection{Synthesis maps and conclusions}

Both city centre inhabitants and adjacent neighbourhood residents use a far greater percentage of the city centre public spaces compared to visitors and tourists. Also, the distribution and variation of visited locations is much greater. The spatial use of residents is therefore less concentrated and also tends to focus more northward. Partially this can be explained by the scattered location of their homes, necessitating longer city centre journeys to reach central destinations.

Figure 7 presents the amalgamation of the spatial use by all respondent groups. When comparing the patterns of spatial use and behaviour of visitors, city centre inhabitants and residents of adjacent neighbourhoods, a few conclusions can be drawn. All groups use the central area and southern portion of the city centre and virtually none of the walking respondents entered the northern area of the city centre. This finding demonstrates that the different respondent groups meet in these central public spaces, offering opportunity for interaction, friction and cultural inference, according to some the very essence of urbanity (Hajer and Reijndorp, 2001). It must be noted that cyclists do use the northern part of the city centre frequently as it accommodates a children's day-care facility.

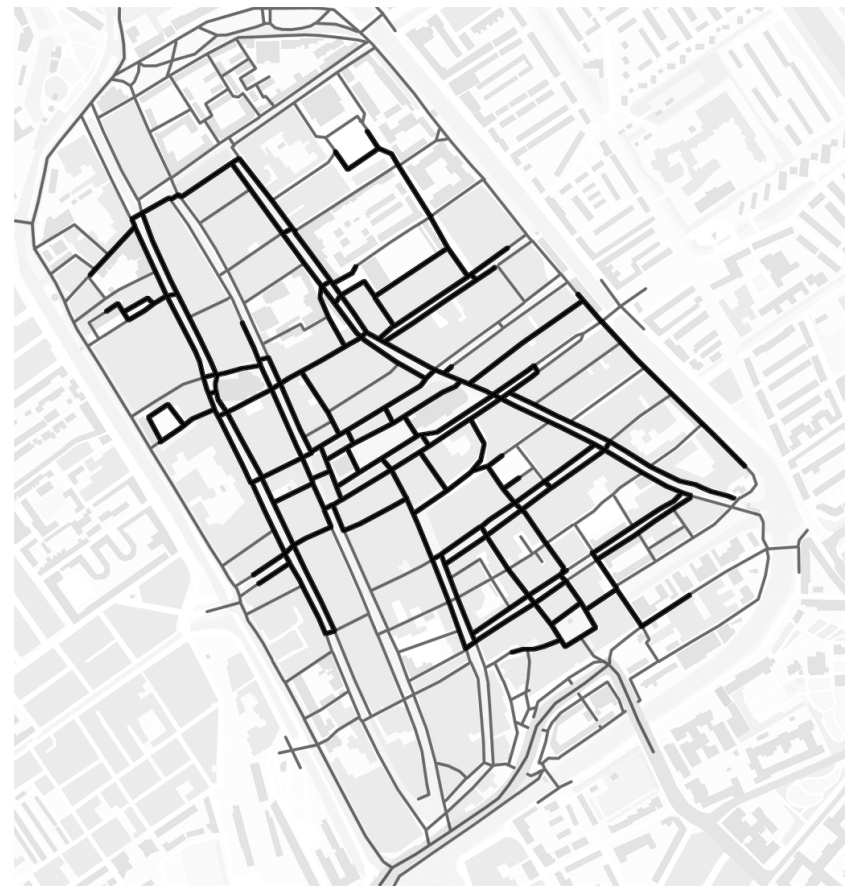

Figure 4. Streets and spaces highly used or unused by city centre inhabitants. Highly used spaces are marked with thick black lines. Unused public spaces are marked in thin grey lines

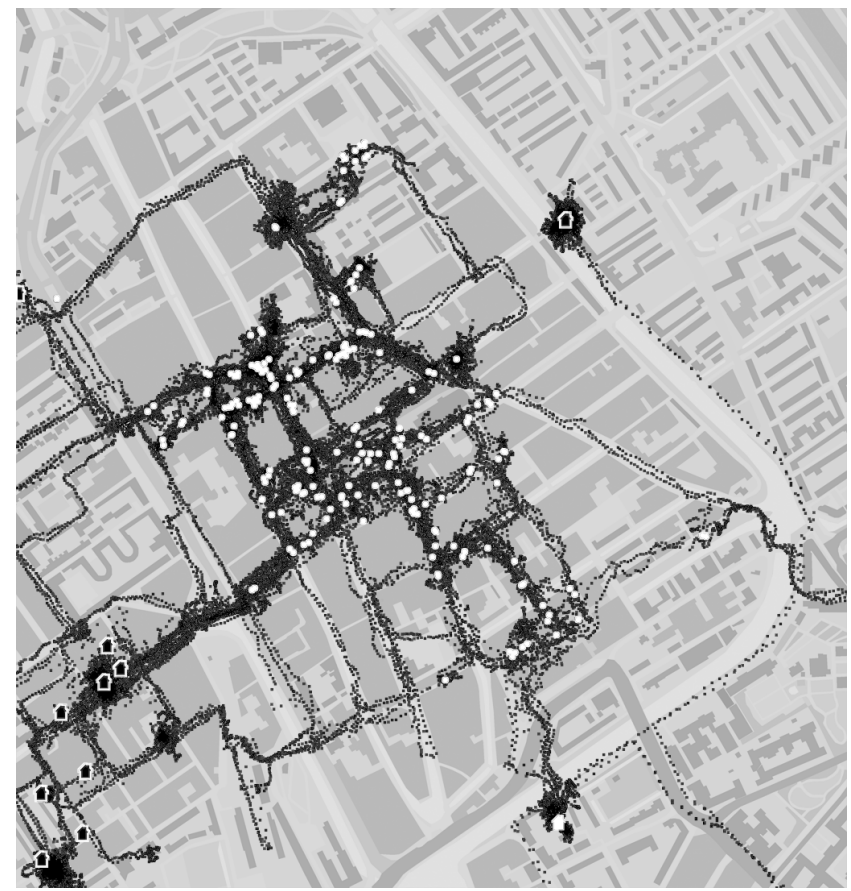

Figure 5. Trips and destinations of adjacent neighbourhood inhabitants 
Urban Design and Planning

Volume 166 Issue DP4
Evidence-based design: satellite positioning studies of city

centre user groups

Van der Spek, Van Langelaar and Kickert

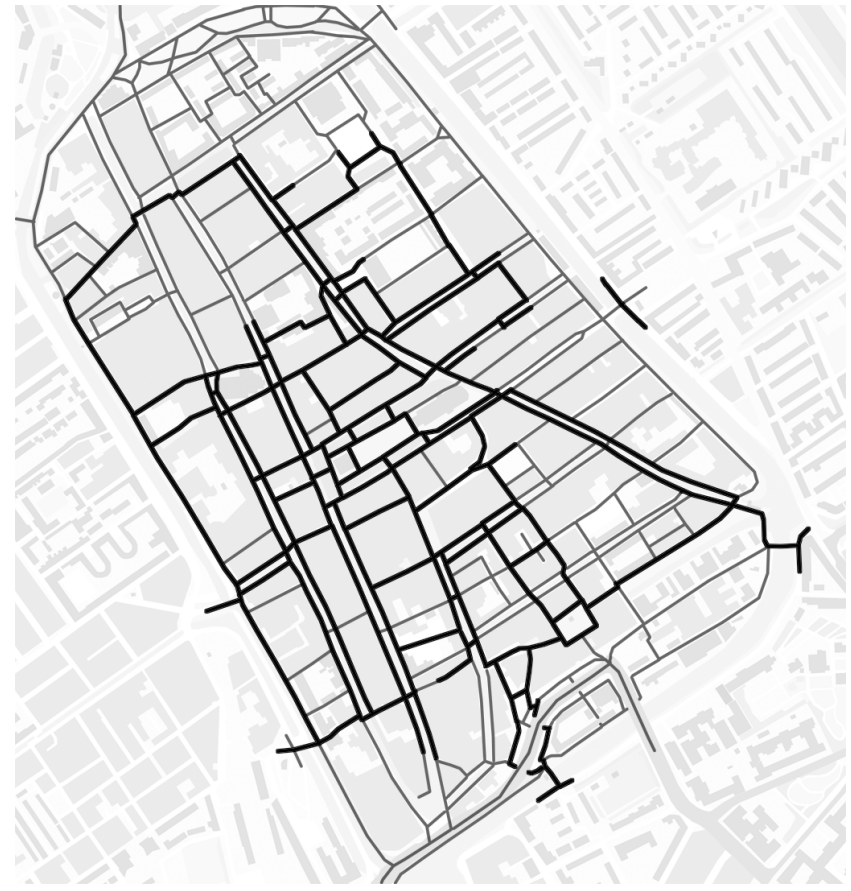

Figure 6. Streets and spaces highly used or unused by adjacent neighbourhood inhabitants

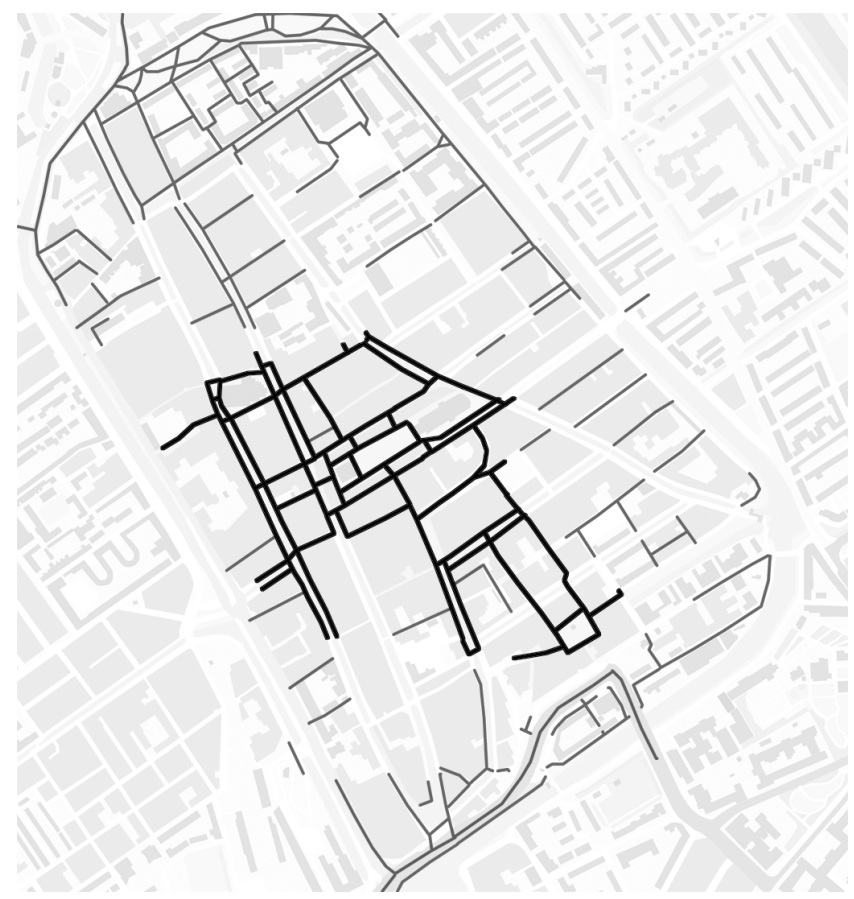

Figure 7. Streets and spaces highly used or unused by all respondent groups. Highly used spaces are marked with thick black lines. Unused public spaces are marked in thin grey lines

\section{City centre evaluation}

Whereas the previous section described patterns of pedestrian activity and public space use in the city centre of Delft, this section focuses on the quality of public space as experienced by visitors and residents. The information is based on post-tracking questionnaires that measured preference and evaluation of public space within the city centre by both visitors and residents. Participants were asked to colour attractive streets green and unattractive streets red. In addition, they were asked to write down why their experiences were good or bad. These experiences are compared and contrasted to existing theories of public space quality in an effort to explain patterns or disparities of human behaviour.

Findings are correlated with the aforementioned activity patterns to uncover similarities and disparities between use and preference. These findings lead to strategic interventions to improve the city centre.

\subsection{Experiences from visitors}

Interestingly, general questionnaire comments pointed towards a division of focus between the accessibility of the city centre and the quality of its public space. As all visitor participants arrived by car, many negative experiences were shared about poor accessibility and the distant placement of car parking garages. The competition of peripheral shopping centres was also mentioned. Yet many of the same respondents did concede that they enjoyed the car-free city centre and valued its safe and uncluttered public spaces. Some respondents looked past the difficult accessibility and judged the city centre by its architectural merits. Others judged the city centre by the amenities offered, appreciating areas with shops and restaurants over 'dead zones' with no public function like dwelling areas. Figure 8 shows the synthesis map of experiences of visitors.

Public spaces that were specifically appreciated by visitors included central places with a high amount of amenities such as shops, supermarkets, restaurants and the library. Independent local shops were specifically mentioned, as they add much needed 'couleur locale' to city centres (Platform Binnenstadsmanagement, 2010). Historic environments were also highly valued as they provide a cosy atmosphere.

Bad experiences in the city centre often pertain to poor accessibility. City centre approaches are deemed unattractive and congested and car parking garages are considered full and poorly signposted. Some respondents actually wished they could park their car on the main market square of the city. Ironically, many poorly valued public spaces are experienced as unsafe owing to intrusion of car traffic, leading to cluttered intersections and narrow sidewalks. Cyclists are also mentioned as adding clutter and decreased safety to the pedestrianised area of the city centre. Social safety also affects 
Urban Design and Planning Volume 166 Issue DP4
Evidence-based design: satellite

positioning studies of city

centre user groups

Van der Spek, Van Langelaar and

Kickert

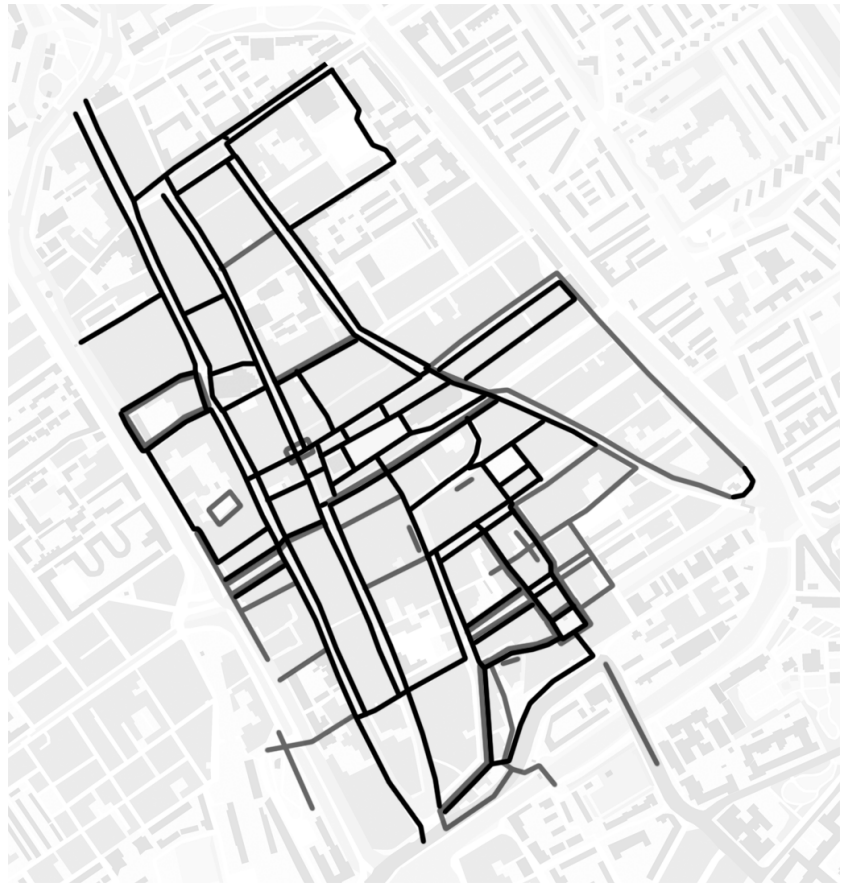

Figure 8. Synthesis map of experiences of visitors. Appreciated spaces are marked with thick black lines. Disliked public spaces are marked in thin grey lines

evaluation: narrow alleyways and pedestrian tunnels are often disliked. Disconnected shopping streets or monuments are also mentioned as a missed opportunity.

The newly designed southern portion of the city centre is a specific target for criticism. Respondents disliked the presence of rowdy youth, but mostly the uninspiring architecture and materialisation of buildings, which many felt was incongruous with the character of the historic part of the city centre. The presence of mostly chain shops does not improve this evaluation as visitors look for independent outlets. Yet others valued the area's easy accessibility and location of a large national supermarket chain, while some even enjoyed the new architecture. It is difficult to pinpoint the mechanisms behind these dichotomous evaluations, and the assessment of taste may prove fruitless: de gustibus non est disputandum.

\subsection{Experiences of inhabitants}

The differences between the evaluation of visitors and inhabitants are subtle and mainly lie in the elements that they emphasise. They often focus on the programmatic aspect of city centre spaces, as streets with local serving retail and restaurants are appreciated over mass-market retail streets and shopping centres. Inhabitants value green spaces for aesthetic pleasure and recreation in the city centre, while vegetation went completely unnoticed by visitors. Coffee shops and bars are often mentioned as a nuisance. This seems to illustrate a more functional rather than experiential approach to the city centre, fitting with the greater exposure of inhabitants to these amenities, even when they are not looking to use them. Figure 9 shows the synthesis map of experiences of inhabitants.

Generally speaking, inhabitants have a more varied opinion about a wider range of public spaces in the city centre. Peripheral spaces that mainly serve locals are often highly valued by inhabitants but are not discovered by visitors. As visitors mainly use the busy core of the city centre, their evaluations often pertain to congestion and conflicts between traffic modalities such as pedestrians, cyclists and cars. Nevertheless, many of the spaces that visitors did not appreciate were equally disliked by inhabitants, for similar reasons: littered streets, unsafe intersections, narrow alleyways and blank facades are unanimously criticised. As with visitors, opinions are split on the newly designed southern retail area.

\subsection{Synthesis}

Respondents' evaluations of city centre public spaces corroborate previous research done by Steffen and Van der Voordt (1979), Korthals Altes and Steffen (1988), Gehl et al. (2006a) and the Municipality of Delft (2009). Their perception of

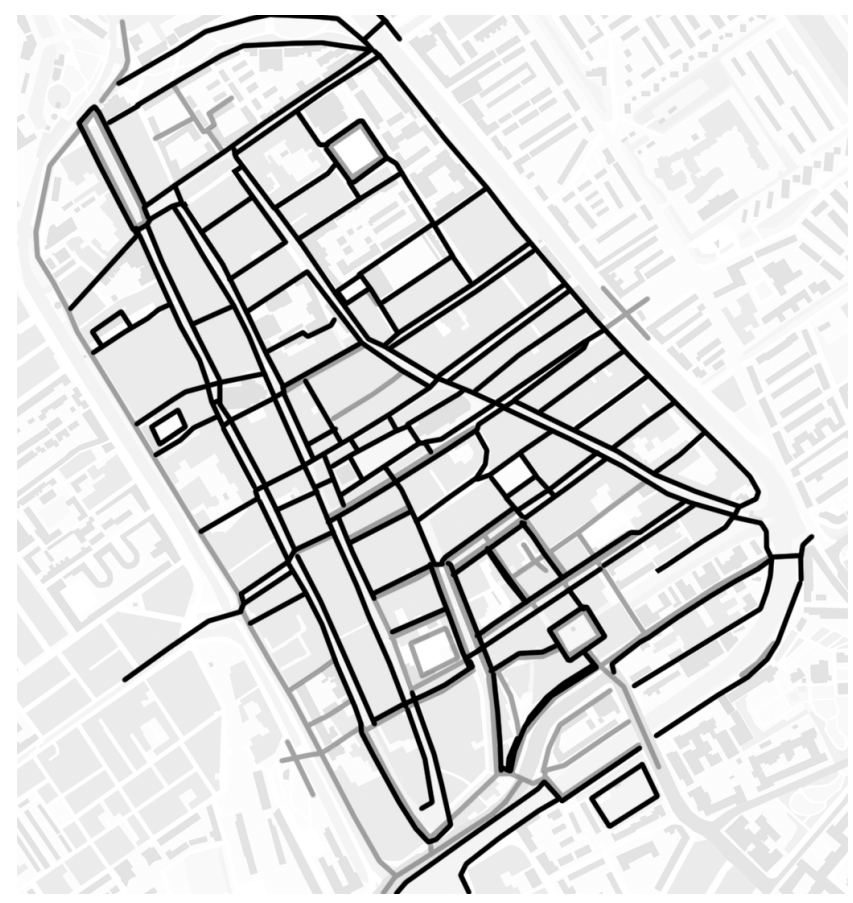

Figure 9. Synthesis map of experiences of inhabitants. Appreciated spaces are marked with thick black lines. Disliked public spaces are marked in thin grey lines 
Urban Design and Planning

Volume 166 Issue DP4
Evidence-based design: satellite

positioning studies of city

centre user groups

Van der Spek, Van Langelaar and Kickert spatial quality can be based on theories of environmental psychology, with visual preference dependent on the visual complexity, coherence, legibility and mystery of environments (Kaplan, 1987). The visual richness and complexity of historic environments is valued by residents and visitors alike, in line with theories of urban evolution (Rapoport, 1990). The coherence of the pedestrianised public realm is valued, but the lack of visual interest of overly coherent environments such as the new southern retail district leads to poor evaluations. Poorly legible and overly mysterious environments such as alleyways and a specifically mentioned pedestrian underpass are disliked. The criticism of poorly maintained public spaces corroborates studies on the significance of order and upkeep in environmental evaluation (Nasar, 1998).

It can be concluded that although the city centre of Delft offers a lot of attractive public spaces intensely used by pedestrians, certain of these popular public spaces are evaluated as poor by respondents. An even larger quantity of high-quality public space is hardly used by visitors or residents. This is probably because these spaces are poorly connected (hidden), too far away from source points, or lack a publicly relevant programme.

Yet spatial behaviour and evaluation are often not independent phenomena. Comparing the evaluation of public space quality with actual measured pedestrian activity leads to the conclusion that pedestrians do stay longer in streets with excellent spatial quality. Streets with low(er) spatial qualities are mostly used as a passing route and not as a place to stay. This is measured by a density analysis made in ArcGIS; it shows concentrations of pedestrians who stay in the public space and destinations as illustrated in Figure 10.

This correlation corresponds to research conducted by Korthals Altes and Steffen (1988), identifying a range of factors affecting route choice of pedestrians in city centres, based on the perceptual, cognitive and emotional amenities of environments, as illustrated in Figure 11. According to Korthals Altes and Steffen, choice motives for routes can be classified into spatial aspects (60\%), functional aspects $(29 \%)$, traffic livability aspects $(9 \%)$ and network aspects $(2 \%)$. The prevalence of spatial aspects in route choice is illustrated by the fact that attractive public spaces in the city centre of Delft are indeed most intensely used, with the caveat that poor public space may still be used for travel, albeit not for sojourning. Owing to the location and importance of certain attractive or important urban facilities these areas are used mostly out of necessity. In this case function can trump form. The close correlation between the functions lining a public space and the use of that space validates the importance of functional aspects on route choice patterns and use of public space.

\section{Interventions}

This section studies how correlations and disparities between public space quality and patterns of use can be embedded in strategic spatial design interventions. These interventions come from comparing pedestrian use and evaluation of public space. As mentioned in the introduction, in an age of dwindling public budgets, investments to improve city centre environments must be prioritised and made with care. Poor public space with high pedestrian exposure lends itself to prioritised

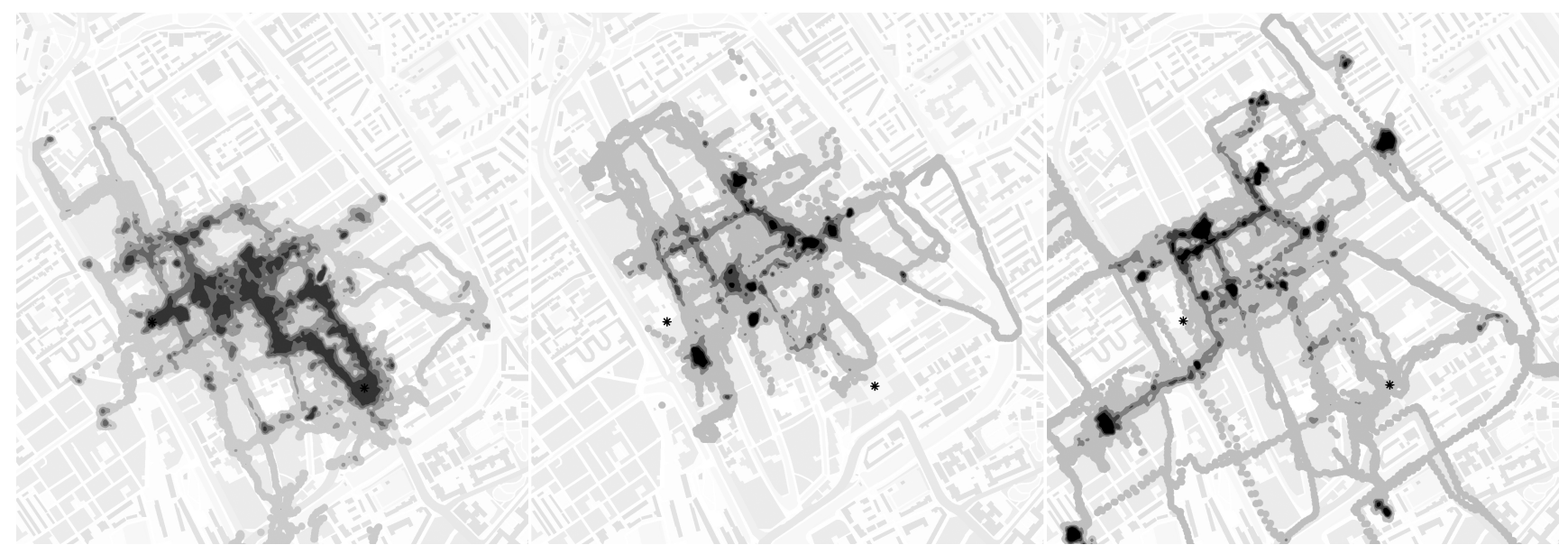

Figure 10. Density analysis on Friday: both garages (left), city centre inhabitants (middle) and neighbourhood residents (right). High concentrations of pedestrians are marked black whereas low concentrations of people show up as (light) grey 
Urban Design and Planning

Volume 166 Issue DP4
Evidence-based design: satellite

positioning studies of city

centre user groups

Van der Spek, Van Langelaar and

Kickert

\begin{tabular}{|c|c|c|}
\hline $\begin{array}{l}\text { Independent } \\
\text { variables }\end{array}$ & $\begin{array}{l}\text { Intermediate } \\
\text { variables }\end{array}$ & $\begin{array}{l}\text { Dependent } \\
\text { variables }\end{array}$ \\
\hline $\begin{array}{c}\text { Urban and architectural } \\
\text { design features }\end{array}$ & Spatial aspects & \\
\hline $\begin{array}{l}\text { Street profile } \\
\text { (height/width) } \\
\text { - Building continuity }\end{array}$ & Privacy/shelter & \\
\hline $\begin{array}{l}\text { Presence of trees } \\
\text { Wealth of detail (e.g. } \\
\text { facades/pavements) } \\
\text { Brightness } \\
\text { Colour/material } \\
\text { - Water presence }\end{array}$ & Visual appeal & $\begin{array}{l}\text { vidual appreciation } \\
\text { spatial quality }\end{array}$ \\
\hline $\begin{array}{l}\text { - Sight line length } \\
\text { - straightness of street } \\
\text { View on landmark } \\
\text { Curved street } \\
\text { Chielded sight }\end{array}$ & $\begin{array}{c}\text { Spatial orientation } \\
\text { and/or } \\
\text { spatial arousal } \\
\end{array}$ & Route choice \\
\hline
\end{tabular}

Figure 11. Design features, spatial qualities and appreciation (Korthals Altes and Steffen, 1988: p. 119)

improvements. High-quality public space that is poorly used should become better connected or at least signposted. Four different vital city strategies are used to determine future directions for a specific area in the city centre, briefly summarised in this section. Figure 12 demonstrates the intervention map where the lines and hatched areas represent four different vital city strategies (Van Langelaar, 2011). To summarise, the matrix in Figure 13 illustrates the connection between use, evaluation and intervention strategies in public space.

The light grey area in Figure 12 would benefit from a 'magnification' strategy as this is the most intensely used area of the city. Public space improvements should be prioritised in this area, as the audience that will benefit from these improvements is far greater than in other areas of the city. Certain hot spots in this intensely used district warrant minor interventions, often to ameliorate legibility, safety and upkeep issues. The solid grey streets of the core shopping area are highly used but also highly valued by visitors and residents alike. Visitors, city centre and adjacent neighbourhood residents use these public spaces and destinations that provide high spatial quality (pedestrians stay here the longest as measured by the GPS survey) and a sufficiently mixed programme, attracting a wide audience. As a result they need not be addressed; these spaces are the focus of the 'consolidation' strategy.

However, the city centre also contains a number of streets frequently used by visitors and residents with a low spatial quality, marked by dark grey lines and areas. These are 'intervention' areas that deserve highly prioritised design and management interventions as they are both intensely used and evaluated as poor. The light hatched areas are earmarked for a 'preservation' strategy. They do not need to be addressed with large investments and interventions. The mainly residential areas in the north, east and

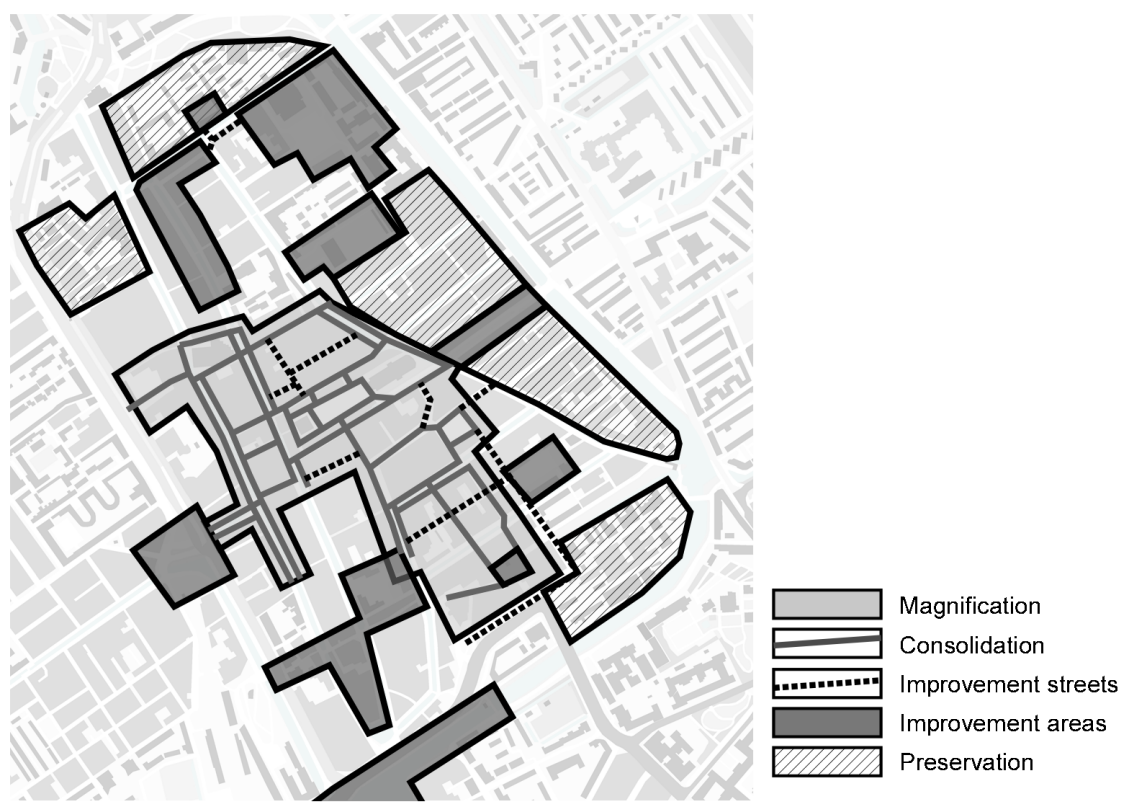

Figure 12. Intervention map, city centre scale of Delft, the Netherlands 
Urban Design and Planning

Volume 166 Issue DP4
Evidence-based design: satellite

positioning studies of city

centre user groups

Van der Spek, Van Langelaar and

Kickert

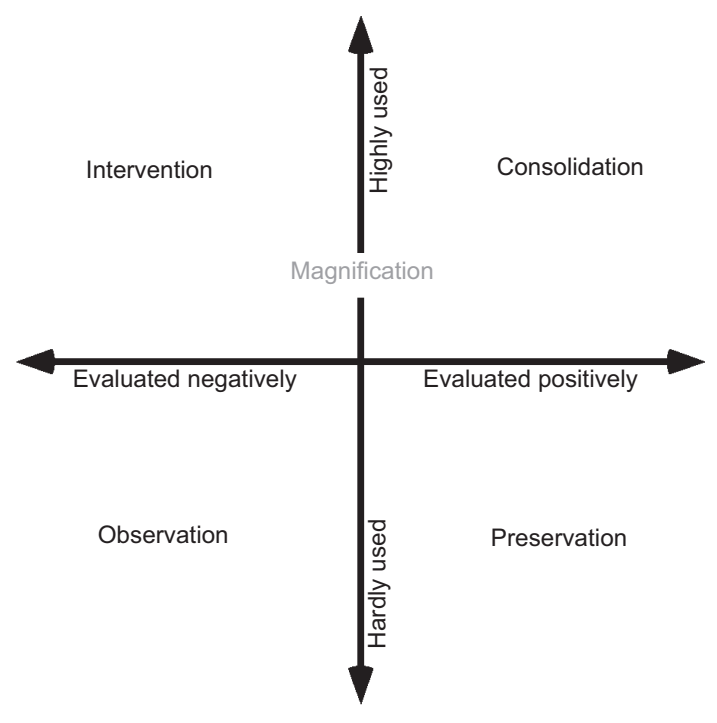

Figure 13. Matrix illustrating the connection between use, evaluation and intervention strategies in public space

south are vital parts in and of themselves without a need for increasing public functions or the quality of public space.

\section{Conclusion and discussion}

In order to improve town and city centre environments for all users, knowing how different social groups use and evaluate public space is fundamental. This paper has focused on public space usage, experiences and quality within urban cores. This study has aimed to compile empirical evidence distilled from two GPS tracking studies illustrating the public space use patterns of three different user groups. The research has proven that streets with good spatial quality attract a variety of people who will stay for a longer time on the streets or visit destinations along the streets. Patterns of public space use also depend on surrounding land uses (activities) and the location of a space inside the urban network (efficiency and accessibility). City life flourishes in those places where locals and visitors can brush shoulders with one another. That is what the city should offer: impulses for unintended and new encounters.

Yet the potential for interventions is not found in the correlation between use and quality, but in the dichotomies between them. Improvements can be prioritised for low-quality streets that are intensively used by pedestrians. The same applies to infrequently visited areas with high-quality public spaces. Although establishing a nomology of human behaviour in public spaces still requires further research, the measurement of this behaviour already has an enormous potential for evidence-based strategic urban design and management interventions. In an age of ever-dwindling public budgets urban design interventions increasingly need to be backed by empirical evidence supporting the claim for improvement.

This paper has presented an approach to this new situation. The authors consider this work to be a continuation of the tradition of bottom-up urbanism - involving city users in an interactive way to improve public space quality. Pedestrians in city centres are a valuable source of information for researchers. Where do people go? Which spaces do they enjoy and which need improvement? This paper mainly aims to present Delft as a case study for research methods that can easily be implemented in other city centres.

As with any research, this case study warrants evolution through further iterations. Besides tracking pedestrians, the current rich database also contains trips that are by bicycle, public transport or car. How do people traverse the city by these transport modes? How does the city centre relate to surrounding neighbourhoods? Do respondents stay in Delft or leave the city for specific activities? To enable higher accuracy and generalisability, research sample sizes could be increased. The amount of time that residents are tracked could be increased from one to three consecutive weeks. Similarly, visitor tracking could take place over multiple weeks. This longer research span also allows the role of national holidays and weather patterns to be taken into consideration.

As GPS research uses the latest technology, metrics are under constant improvement. High-density areas such as city centres may suffer from signal reflections due to surrounding buildings. This may be ameliorated by deploying accelerometers or gyroscopes to improve signals and resolution. Mobile phones can be tracked either actively through installing applications or passively in cooperation with mobile phone providers. Similarly, Bluetooth technology in combination with location-based questions may drastically increase sample sizes, thus far unfortunately at the expense of data accuracy. A combination of these technologies with more conventional methods such as mind mapping or footfall counts can fill in most methodological gaps as each approach has its advantages and disadvantages. All things considered, the mapping of behaviour and evaluation may mark a new era of interactive and evidence-based design of urban environments.

\section{REFERENCES}

Appleyard DM, Gerson S and Lintell M (1981) Livable Streets. University of California Press, Berkeley, USA. Carmona M (2010) Public Places - Urban Spaces: The Dimensions of Urban Design, 2nd edn. Elsevier/ Architectural Press, London, UK.

Coleman P (2006) Shopping Environments: Evolution, Planning and Design. Elsevier/Architectural Press, London, UK. Gehl J (1971) Life Between Buildings: Using Public Space, 6th 
Urban Design and Planning

Volume 166 Issue DP4
Evidence-based design: satellite

positioning studies of city

centre user groups

Van der Spek, Van Langelaar and

Kickert edn (2010 edn). The Danish Architectural Press,

Copenhagen, Denmark.

Gehl J, Johansen Kaefer L and Reigstad S (2006a) Close encounters with buildings. Urban Design International 11(1): 29-47.

Gehl J, Gemzøe L, Kirknaes S and Sternhagen Søndergaard B (2006b) New City Life. The Danish Architectural Press, Copenhagen, Denmark.

Hajer M and Reijndorp A (2001) In Search of New Public

Domain: Analysis and Strategy. NAi Publishers,

Rotterdam, the Netherlands.

Jacobs J (1961) The Death and Life of Great American Cities. Random House, New York, USA.

Jakle J and Sculle K (2004) Lots of Parking: Land Use in a Car Culture. University of Virginia Press, Charlottesville, USA.

Janssens D, Hannes E and Wets G (2008) Tracking down the effects of travel demand policies. In Urbanism on Track: Application of Tracking Technologies in Urbanism (Van Schaick J and Van der Spek SC (eds)). IOS Press, Amsterdam, the Netherlands, pp. 147-160.

Kaplan S (1987) Aesthetics, affect and cognition: environmental preference from an evolutionary perspective. Environment and Behavior 19(1): 3-32.

Korthals Altes HJ and Steffen C (1988) Beleving en Routekeuze in de Binnenstad van Delft. Delft University Press, Delft, the Netherlands.

Montgomery J (1998) Making a city: Urbanity, vitality and urban design. Journal of Urban Design 3(1): 93-116.

Municipality of Delft (2009) Samenvatting Draagvlak Autoluwe Binnenstad. DIP, Delft, the Netherlands, see http://www. delft.nl/Inwoners/Gemeente_en_democratie/ Democratie_en_inspraak/Delft_Internet_Panel_DIP/ Resultaten_DIP/2009 (accessed 27/12/2010).

Nasar JL (1998) The Evaluative Image of the City. Sage Publications, Thousand Oaks, CA, USA.

Platform Binnenstadsmanagement (2010) Signalen uit de Binnenstad. Drukkerij Tielen, Boxtel.

Plowden B (2010) Encouraging walking in an age of austerity.
In Proceedings of the XI International Conference on Walking and Liveable Communities. Walk21, The Hague, the Netherlands.

Rapoport A (1990) History and Precedent in Environmental Design. Plenum Press, New York, USA.

Shoval N and Isaacson M (2010) Tourist Mobility and Advanced Tracking Technologies. Routledge, New York, USA.

Steffen C and Van der Voordt DJM (1979) Delft, een Analyse van de Belevingswaarde. TH Delft, Delft, the Netherlands.

Taubman A (2007) Threshold Resistance: The Extraordinary Career of a Luxury Retailing Pioneer. HarperCollins Publishers, New York, USA.

Van der Hoeven FD, Smit MGJ and Van der Spek SC (eds) (2008) Pedestrian Mobility and the Regeneration of the European City Centre. Street-Level Desires: Discovering the City on Foot. TU Delft, Delft, the Netherlands.

Van der Spek SC (2008) Spatial Metro: tracking pedestrians in historic city centres. In Urbanism on Track: Application of Tracking Technologies in Urbanism (Van Schaick J and Van der Spek SC (eds)). IOS Press, Amsterdam, the Netherlands, pp. 79-102.

Van der Spek SC, Van Schaick J, De Bois PG and De Haan R (2009) Sensing human activity: GPS tracking. Sensors 9(4): 3033 3055, http://dx.doi.org/10.3390/s90403033.

Van Langelaar CM (2011) Measure, Understand and Improve Cities; Visualizing Pedestrian Flows to Improve Inner-City Quality in Delft Using GPS-Tracking Technology. Masters thesis, Delft University of Technology, Delft, the Netherlands.

Van Schaick J and Van der Spek SC (2007) Application of tracking technologies in spatial processes: an exploration of possibilities. In Proceedings of Conference REAL CORP 007: To Plan Is Not Enough. Realcorp, Vienna, Austria.

Van Schaick J and Van der Spek SC (eds) (2008) Urbanism on Track: Application of Tracking Technologies in Urbanism. IOS Press, Amsterdam, the Netherlands.

Whyte WH (1988) City: Rediscovering the Center (2009 edn). Pennsylvania Press, Philadelphia, USA.

\section{WHAT DO YOU THINK?}

To discuss this paper, please email up to 500 words to the editor at journals@ice.org.uk. Your contribution will be forwarded to the author(s) for a reply and, if considered appropriate by the editorial panel, will be published as discussion in a future issue of the journal.

Proceedings journals rely entirely on contributions sent in by civil engineering professionals, academics and students. Papers should be 2000-5000 words long (briefing papers should be $1000-2000$ words long), with adequate illustrations and references. You can submit your paper online via www.icevirtuallibrary.com/content/journals, where you will also find detailed author guidelines. 